\title{
O Jornalismo em forma de carta no primeiro século da Era Cristã: análise das epístolas bíblicas de São Paulo a partir das principais características jornalísticas
}

KeVin Willian Kossar FURTAdo

Universidade Estadual de Ponta Grossa (UEPG) - E-mail: kevin@aol.com.br Jornalista e mestrando do Programa de Pós-Graduação em Ciências Sociais Aplicadas pela UEPG. Editor associado da Revista Brasileira de Ensino de Jornalismo (REBEJ) e editor do site Cultura Plural (www.culturaplural.com.br).

SÉRGIO LUIZ GADINI

Universidade Estadual de Ponta Grossa (UEPG) - E-mail: sergiogadini@yahoo.com.br Jornalista pela Universidade Federal de Santa Maria (UFSM), mestre em Comunicação e Cultura Contemporânea pela Universidade Federal da Bahia (UFBA) e doutor em Ciências da Comunicação pela Universidade do Vale do Rio dos Sinos (Unisinos). Coordenador do Mestrado em Jornalismo da UEPG.

\begin{abstract}
Resumo
O estudo identifica características do Jornalismo em seis cartas bíblicas (Novo Testamento) de São Paulo. As referências de Jornalismo pautam-se nas obras dos alemães Tobias Peucer (2004) e Otto Groth (apud FAUS BELAU, 1966) que, no fim do século XVII e primeira metade do século $\mathrm{XX}$, respectivamente, sistematizaram as noções elementares que historicamente definiram $\mathrm{O}$ Jornalismo. O trabalho também discorre sobre as formas embrionárias/pré-históricas suportadas pelo Jornalismo, conforme Jorge Pedro Sousa, Luiz Beltrão e Carlos Rizzini, e discute o papel essencialmente informativo desempenhado pelas cartas ao longo da história registrada. As cartas paulinas podem ser consideradas como formas protojornalísticas. Elas reúnem-se grupo dos fenômenos pré-jornalísticos do mundo antigo, com base nos exemplos de Jorge Pedro Sousa (2008).
\end{abstract}

Palavras-chave

Jornalismo; cartas bíblicas; fenômenos pré-jornalísticos. 
Estudos em Jornalismo e Mídia - Vol. $10 \mathrm{~N}^{\circ} \mathrm{I}$ - Janeiro a Junho de 2013

ISSNe 1984-6924

DOI: http://dx.doi.org//0.5007//984-6924.2013vI0nIpl83

\section{Abstract}

This study identifies Journalism characteristics in six biblical letters from Saint Paul (New Testament). The references of Journalism are based on the works of German authors Tobias Peucer (2004) and Otto Groth (apud FAUS BELAU, 1966), who, in the end of the $18^{\text {th }}$ century and first half of $20^{\text {th }}$ century, respectively, codified the elementary notions that have historically defined the Journalism. This study also talks about the embrionary/prehistoric forms supported by Journalism, according to Jorge Pedro Sousa, Luiz Beltrão and Carlos Rizzini, and debates the function also informative played by the letter throughout registered history. The pauline letters can be considered as forms protojournalistic. They gather the group of pre-journalistic phenomena of the ancient world, based on examples of Jorge Pedro Sousa (2008).

\section{Keywords}

Journalism; biblical letters; phenomenon pre-journalistic.

Artigo recebido em 20/05/2013

Aprovado em 18/06/2013 
Estudos em Jornalismo e Mídia - Vol. $10 \mathrm{~N}^{\circ} \mathrm{I}$ - Janeiro a Junho de 2013

\section{Práticas missivistas como manifestações jornalísticas}

O Jornalismo já comportou diferentes formatos ao longo da história e a consolidação do campo parte da especialização dos meios de informação, que têm sua origem na intrínseca necessidade humana de comunicar fatos e partilhar opiniões sobre temas que permeiam o cotidiano. Nesse sentido, as cartas funcionaram como um estágio da comunicação interpessoal que precedeu e que tinha a função social ora desempenhada pelo jornalismo informativo, conforme seu modelo hegemônico, pósRevolução Industrial.

O exercício do Jornalismo já registrou diferentes funções, em sintonia com demandas, limitações ou condições históricas. Não seria, pois, razoável que se considerasse, neste momento atual, como prática jornalística apenas o que está em vigor. Este passeio histórico tem um papel importante, pois opera como contextualização, justificativa e fundamentação conceitual que possibilita pensar o objeto do estudo em uma leitura (abordagem) jornalística.

Do material bibliográfico recente, a maioria dos estudos compreende as cartas apenas como manifestação opinativa em jornal impresso, não levantando outras variáveis/possibilidades de funções jornalísticas (ou rudimentarmente jornalísticas) das práticas missivistas. Nessa linha de abordagem, são notáveis os trabalhos de Beltrão (1980), Chaparro (1992) e Marques de Melo (2003).

Sobre uma visão jornalístico-informativa das cartas, encontra-se em Rizzini (1977, p. 59-60) a noção de que as cartas circulantes entre os séculos XVI e XVIII, sobretudo na Europa, possuíam maior conteúdo jornalístico, no sentido informativo, do que a maioria das folhas e gazetas que circulavam na época. De volta a Roma, no tempo das Actas Urbanas, o autor assegura que "[a]s cartas ocupavam então o lugar dos jornais e prestavam os mesmos serviços" (1977, p. 9). Sobre a função jornalística das cartas, Boissier (apud RIZZINI, 1977, p. 9) relata que do "gênero de cartas parece [...] ser possível dizer que quase ocupavam, num limitado círculo, o lugar dos jornais de hoje". Alcides Lemos endossa tal noção e as aponta como "o mais antigo veículo de 
Estudos em Jornalismo e Mídia - Vol. $10 \mathrm{~N}^{\circ} \mathrm{I}$ - Janeiro a Junho de 2013

comunicação social (anterior mesmo à tipografia), a mais pura forma de jornalismo" (apud MARQUES DE MELO, 2003, p. 177).

\section{Carta como (possível) veículo jornalístico}

Rizzini (1977) destaca as Actas Urbanas da capital do Império pela feição oficial e tendenciosa, o que levava os letrados e estadistas e recorrer uns aos outros para se manterem informados dos principais acontecimentos ocorridos dentro e fora da cidade.

Mesmo com o surgimento e consolidação da tipografia, que impulsionou a impressão de materiais impressos informativos, as cartas, no período que compreende os séculos XVI a XVIII, ainda satisfaziam a necessidade de contar novidades. A continuidade de tal uso se justifica, segundo Rizzini, pela fartura de papel, pela normalidade dos usos missivistas, que escapavam de qualquer tipo de censura e por conta do trânsito nos meios aristocratas e palacianos e nas rodas de letrados e influentes, preocupadas com a vida pública.

Já na segunda metade do século XVIII, em tempos de diálogo entre o despotismo esclarecido e o 'intelectualismo', Rizzini lembra que os literatos e eruditos passaram a transitar pelo gazetismo. Poetas, reis, filósofos e príncipes "carteavam-se" entre si. Para o autor, existem inúmeras coleções missivistas do período, destacando-se os 17 volumes da correspondência de um alemão de Ratisbona, aguçado crítico literário chamado Grimm que, em companhia de Diderot e Madame d'Épinay, durante 37 anos (de 1753 a 1790), manteve os nobres inteirados dos acontecimentos mundiais refletidos em Paris: Grande Catarina, Frederico da Prússia, a landgravina de Hesse, Carolina, e o grão-duque da Toscana. "Grimm exerceu a apreciação epistolar das idéias, das belas letras e das belas-artes como a exerceriam no século seguinte os profissionais dos jornais e revistas", diz Rizzini (1977, p. 83).

Como se vê, a prática de informar por carta é bem anterior à invenção da imprensa (século XV). Assim, pode-se dizer que, na era pré-Gutenberg, tal prática 
Estudos em Jornalismo e Mídia - Vol. $10 \mathrm{~N}^{\circ} \mathrm{I}$ - Janeiro a Junho de 2013

estava associada ao jornalismo, aqui entendido como circulação de informações de interesse público. E, pois, na perspectiva histórica, pode-se entender que as práticas missivistas - ainda que manuscritas e restritas ao pequeno universo de leitores com domínio da linguagem gráfica - operavam, antes mesmo do jornalismo industrial, como uma pré-história do Jornalismo moderno.

Não há, contudo, um momento pontual na história do Jornalismo em que as cartas passam a ser 'enquadradas' como gênero de opinião. Mas, tal caracterização deriva de um modelo crescentemente hegemônico de estrutura discursiva que o Jornalismo adapta das ciências humanas, em suas variadas influências temáticas, estruturais ou de formatação expressiva. Como se vê, o exercício do Jornalismo já registrou diferentes funções e mesmo formatos, em sintonia com demandas, limitações ou condições históricas. Não seria, pois, razoável que eventualmente se considerasse, apenas, como prática jornalística - ainda que, no atual modelo globalizado, seja de fato hegemônico - o que se mostra mais visível ou forte em termos de produção, circulação e consumo de mídia nas sociedades contemporâneas.

Por fim, vale ponderar que esta reflexão, na forma de um breve passeio histórico, pretende dialogar, por um lado, com as construções históricas dos modelos hegemônicos da produção jornalística e, de outro aspecto, tencionar as formas mais expressivas - ou que também se tornaram quase consensuais - de se pensar e contar a História do Jornalismo. Não se trata de ignorar o que se entende por Jornalismo, na perspectiva das sociedades ocidentais modernas, mas de trazer à luz um aspecto que visa considerar os diversos momentos que fizeram e se constituíram em práticas de produção jornalística. Ao que tudo indica, neste aspecto, é preciso ter presente e não esquecer que o hábito de escrever cartas já foi uma importante marca da expressão jornalística ao longo da história da humanidade.

\section{Fenômenos pré-jornalísticos/formas embrionárias de Jornalismo}

Jorge Pedro Sousa defende que não existe um pensamento único sobre a História do Jornalismo e uma única versão que explique seu surgimento. Para o autor, tal 
Estudos em Jornalismo e Mídia - Vol. $10 \mathrm{~N}^{\circ} \mathrm{I}$ - Janeiro a Junho de 2013

entendimento passa por seis considerações basilares, nem sempre consensuais na comunidade acadêmica, dentre as quais aqui interessam: a gênese do Jornalismo encontra-se na Antiguidade Clássica, e retorna na Idade Moderna, por conta do Renascimento, do espírito iluminista e da satisfação das condições técnicas e sócioeconômicas para seu desempenho; a notícia se apresenta como determinante e identificadora do Jornalismo e dos fenômenos pré-jornalísticos, onde os valores-notícia permanecem estáveis/similares ao longo do tempo; tanto o discurso pré, como o discurso jornalístico, no que diz respeito aos conteúdos e formatos, em todas as eras, possui uma natureza sócio-cultural e reúne a ideologia, o contexto e sofre influência dessas variáveis e de outras, como a interferência de quem o elabora, além dos potenciais e limites dos dispositivos técnicos usados; desde o século XVII existiam "gazeteiros", "periodistas", que viviam de produzir notícias, antes da profissionalização do trabalho dos jornalistas no século XIX, o qual representa a reformatação de um modelo que já existia na Antiga Roma; e, o compreender o jornalismo e suas teorias contemporâneas, implica compreender sua evolução (2008, p. 3-4).

Segundo o português, das ideias acima, a primeira é a mais controversa. Pizarroso Quintero apresenta as três visões predominantes sobre a origem dos fenômenos jornalísticos; as duas primeiras "sócio-culturais" e a terceira "técnica": a primeira situa a existência de práticas jornalísticas desde a Antiguidade, visto que à época existia dispositivos que transmitiam, regular e organizadamente, informações atuais, processo que encerra a definição básica da técnica de troca de notícias; a segunda trata o jornalismo como uma invenção da modernidade, ligado à criação da tipografia e à consolidação da periodicidade da imprensa na Europa; e a última determina o nascimento do jornalismo no século XIX, quer devido ao surgimento de dispositivos técnicos que possibilitaram a massificação dos jornais, ou por conta da invenção de instrumentos que facilitaram a transmissão da informação à distância, caso do telégrafo e dos cabos submarinos e também pela obtenção mecânica de imagens. É nesse quadro que teriam surgido as agências de notícias internacionais (1996, p. 8-11 apud SOUSA, 2008 , p. 4). No presente texto, assume-se a visão de que a gênese do Jornalismo 
Estudos em Jornalismo e Mídia - Vol. $10 \mathrm{~N}^{\circ} \mathrm{I}$ - Janeiro a Junho de 2013

encontra-se em fenômenos embrionários e nas formas pré-jornalísticas da Antiguidade e até mesmo na pré-história, conforme se vê em Beltrão (1992).

\section{Fenômenos pré-jornalísticos na Antiguidade}

Segundo Beltrão (1992, p. 33-34), o homem primitivo, e o das cavernas, mesmo não conhecendo a escrita, já faziam Jornalismo, visto que transmitia aos seus semelhantes ou à sua tribo, regularmente e de maneira interpretativa, os fatos que interessavam à comunidade, como o resultado da pesca e da caça, a aproximação de animais ferozes, fenômenos da natureza, a escolha de líderes dos grupos/tribos e o relato das batalhas. Beltrão remonta o que classifica de fase pré-histórica do Jornalismo a documentos conservados, como as inscrições gravadas por Yu, o Grande, sobre o monte Heng-Chan, na China, que datam de cerca de 2.200 a.C. (1992, p. 34); e o Mármore de Paros, encontrado no século XVI, onde se podia acompanhar o cotidiano da fundação de Atenas. O autor faz referência a Flavius Josephus, para quem "os babilônios contavam com historiógrafos, encarregados de escrever o resumo dos acontecimentos públicos" e que o material teria sido utilizado por Bérose, que compôs no século III a.C. a História da Caldeia (1992, p. 34).

Segundo o autor, Voltaire escreveu que a China possuía jornais desde tempos imemoriais e, ainda que, "sem comprovação absoluta, em 1908 foi comemorado, naquele país, o milênio da Gazeta de Pequim (King Pao) que, segundo a tradição, era escrita em madeira" (1992, p. 34). Conforme Beltrão, para onde quer que se pretenda ir à antiguidade, encontra-se, seja em pedra, pau, metal, barro, concha, fibra, pele e papel, formas de jornal e formas de informação rudimentar de algum acontecimento, conservado pelos símbolos ${ }^{1}$.

Sousa considera as Actas Romanas (conhecidas como Actas Diurnas, [Actae Diurnae], Actas Públicas, Actas Urbanas ou ainda Diurnálias) como antepassados mais antigos dos modernos jornais, os veículos de inclinação “jornalística”, que primeiro

\footnotetext{
${ }^{1}$ RIZZINI, Carlos. O livro, o jornal e a tipografia no Brasil. Rio de Janeiro: Livraria Kosmos Editora, 1946. p. 12-13 apud BELTRÃO, 1992, p. 35.
} 
Estudos em Jornalismo e Mídia - Vol. $10 \mathrm{~N}^{\circ} \mathrm{I}$ - Janeiro a Junho de 2013

surgiram no mundo. $\mathrm{O}$ autor diz que as Actas surgiram provavelmente em Roma, no século II a.C. (por volta de 131 a.C.). Quem recolhia, redigia e fixava as Actas eram os magistrados, os escravos e os funcionários públicos, que podem ser considerados os "primeiros jornalistas", na função de repórteres ou correspondentes. Sousa resume as características das Actas Diurnas similares às dos jornais modernos: periodicidade mais ou menos regular, em determinados momentos, diária; frequência de publicação; conteúdos com caráter noticioso, onde a notícia é a base da informação; corpo de escritores (escribas, os diurnarii ou actuarii, classificados como os "primeiros jornalistas"), encarregados de redigir as atas; difusão pública e à distância da informação, com caráter "massivo"; uso de variados suportes, como jornal de parede e manuscrito; e iniciativa editorial do Estado e de particulares (2008, p. 42-43).

O contexto medieval pouco contribuiu ao surgimento/desenvolvimento de fenômenos pré-jornalísticos, segundo referências de Jorge Sousa. Não obstante, algumas formas pré-jornalísticas podem ser citadas, como as crônicas, cartas informativas e os relatos de viagens.

\section{Formatos pré-jornalísticos no Renascimento}

O período renascentista contribuiu, entre os séculos XIV e XVI, para a proliferação de publicações, tanto manuscritas, como impressas. Um evento de singular importância à época foi a invenção do sistema tipográfico de Gutenberg, entre 1444 e 1456, na Alemanha. A consolidação da cultura escrita impulsionou o aparecimento de antecessores do Jornalismo atual, como as crônicas, cartas e almanaques. Mas, as cartas também se sustentaram como relevante meio de transmissão de informações no Renascimento (2008, p. 56).

Sousa considera as folhas volantes (também conhecidas como folhas ocasionais, noticiosas ou de relações) como um dos principais dispositivos pré-jornalísticos do Renascimento - perdurando até o século XIX -, se perpetuando inclusive à contemporaneidade, se se considerar as folhas panfletárias noticiosas. O autor circunscreve o aparecimento das folhas volantes na Itália, mais precisamente em Veneza 
Estudos em Jornalismo e Mídia - Vol. $10 \mathrm{~N}^{\circ} \mathrm{I}$ - Janeiro a Junho de 2013

e Gênova. O autor assegura que elas se difundiram rapidamente por toda Europa, vendidas em feiras e outros espaços. Para ele, as folhas volantes, juntamente com os livros e os opúsculos noticiosos (que eram coletâneas de notícias que apareceram, aproximadamente, em 1587), formam o conjunto dos principais antecessores diretos dos jornais atuais e se configuram como a maior contribuição do Renascimento ao jornalismo (2008, p. 58).

A mais antiga folha volante de que se tem notícia, assinala Sousa $(2008$, p. 5960), foi editada em Bolonha, na Itália, em 1470. Sousa salienta, contudo, que no Oriente, também se publicou uma espécie de folha volante, os Yomiuri (“paga e lê”), no Japão, porém, tão somente no século XVII (2008, p. 68).

Para Scheneider (1996, p. 114), o primeiro jornal mensal foi o Annus Christi, da Alemanha, em 1579, em Rorschach Bodensee. E os primeiros semanários teriam surgido em 1609. O Die Relation, editado em Estrasburgo por Johann Carolus, e o Aviso, produzido pelo impressor Julius Adolph von Söhne, segundo ela, inauguraram uma "nova modalidade de jornalismo que rapidamente encontrou imitadores em Colónia, Francoforte, Hamburgo e outros lugares, situados sobretudo ao longo das rotas comerciais" (SCHENEIDER, 1996, p. 115). Em conclusão, Sousa destaca que "muitos dos conteúdos e formatos do jornalismo contemporâneo se encontram [...] na literatura [...] há milénios" (2008, p. 19).

O presente estudo, a partir das referências de suportes/dispositivos pré-jornalísti$\cos$ - ou que encerravam formas embrionárias de jornalismo - situados ao longo da história, objetiva identificar características do jornalismo em seis cartas bíblicas (Novo Testamento) de São Paulo, além de apontar um modelo de comunicação das epístolas paulinas que podem ser considerados como uma pré-história do jornalismo por serem similares às características conceituais históricas que definem o campo; e, também, levantar elementos que possibilitem (re)pensar as versões hegemônicas da História do Jornalismo, que se limitam (majoritariamente) em discutir o assunto a partir da invenção da imprensa. 
Estudos em Jornalismo e Mídia - Vol. $10 \mathrm{~N}^{\circ} \mathrm{I}$ - Janeiro a Junho de 2013

\section{Características do Jornalismo, a partir de Tobias Peucer}

O alemão Tobias Peucer produziu a primeira tese sobre Filosofia do Jornalismo apresentada em uma instituição de ensino superior de que se tem registro, feito realizado em 1690, na Universidade de Leipzig, Alemanha. 'De relationibus novellis' traça, em 29 parágrafos, uma comparação entre o Jornalismo e a História. Tal reflexão, produzida há mais de 300 anos, mostra que as noções que ora definem o Jornalismo e suas práticas não se constituem, simplesmente, de uma invenção moderna, do pós-Revolução Industrial e pós-Iluminismo, mas como resultado de uma atuação profissional (e, em alguns casos - sobremaneira vistos na Idade Média, por conta da censura prévia -, amadora e clandestina) que acompanha a história humana há pelo menos 2.000 anos, se contarmos do tempo das Actas Urbanas do Império Romano, mesmo que essa, logicamente, não possua os mesmos contornos do que hoje concebemos e aceitamos como Jornalismo.

No parágrafo II, Peucer (2004, p. 15) discorre sobre os usos de termos empregados na tese, e sua relação com a noção de relato/notícia. No parágrafo seguinte Peucer indica o que denomina como as diversas formas de história. Já no quarto parágrafo (2004, p. 16), ele define as relationes (relatos) como relatos periodísticos (Relationes novellae), que é a notificação de diversos ocorridos recentemente em qualquer lugar que seja.

Peucer explica, no sexto parágrafo, que - até o momento de produção de sua tese - era impossível assinalar onde originaram-se os relatos e quando, pela primeira vez, começou-se a escrevê-los. $\mathrm{O}$ autor indica o descuido de povos de registrar sua história. A exemplo dos gregos que, segundo ele - se referindo a Diodor de Sicília no início de sua 'Bibliotheca historica' -, não davam nenhuma atenção à história antes da guerra de Troia. "Muito pelo contrário, antes das Olimpíadas, tudo restava desconhecido e envolto em faltas", explica Peucer (2004, p. 16).

No parágrafo X Peucer salienta o testemunho ocular dos acontecimentos como um critério de seleção dos "relatos". Em seguida (parágrafo XI) ele menciona que, na produção dos relatos, deve haver uma separação entre o que é relevante e o que é banal, 
Estudos em Jornalismo e Mídia - Vol. $10 \mathrm{~N}^{\circ} \mathrm{I}$ - Janeiro a Junho de 2013

culminando na publicação daquilo que seja de interesse público, que é ordenado na tese como o juízo, "a mais exímia qualidade do intelecto, para que, por meio dele, as coisas dignas de crédito sejam separadas dos rumores infundados que se fazem correr; as leves suspeitas e as coisas e ações diárias sejam separadas das coisas públicas e daquelas que merecem ser contadas" (PEUCER, 2004, p. 18). A veracidade, por sua vez, desponta como mais uma característica dos relatos periodísticos (parágrafo XIII). Para Peucer, os constrangimentos partidários devem ser deixados de lado, para que nada de falso interfira na produção das notícias ou sejam escritas coisas insuficientemente exploradas (2004, p. 19).

Os primeiros 14 parágrafos da tese de Peucer diziam respeito às características autorais dos relatos. Em seguida, o estudo destaca as particularidades das 'matérias' dos periódicos que, para ele, são os acontecimentos singulares, os fatos realizados por Deus através da natureza, pelos anjos ou pelos homens na sociedade civil e na Igreja, e, "como estes fatos são quase infinitos, cabe estabelecer uma seleção de modo que seja dado preferência [...] àqueles que merecem ser recordados ou conhecidos" (PEUCER, 2004, p. 20).

Em contraponto, no parágrafo XVI, Peucer apresenta o que não deve ser considerado digno de atenção jornalística, como as ações diárias dos homens e suas desgraças comuns, tempestades regulares, atos privados dos governantes e conjecturas sobre os afazeres públicos $(2004$, p. 21). E, precisamente no parágrafo XXI, Peucer traça um modo de estruturação do texto que se assemelha ao lead, sinônimo de distinção da escrita jornalística em relação às demais, tida como invenção anglo-saxônica do século XIX.

No parágrafo XXII o teórico descreve a linguagem a ser empregada nos relatos e, citando Cícero, Lúcia, Fábio Quintiliano e Plínio, dá subsídios e exemplos que demonstram o caráter claro e conciso exigido dos textos. Combate as palavras que são de difícil compreensão para a média dos leitores, bem como as confusões de ordem sintática e as gírias, para que a maioria assimile claramente o que é dito e para que os eruditos sintam-se satisfeitos com a leitura (2004, p. 24). 
Estudos em Jornalismo e Mídia - Vol. $10 \mathrm{~N}^{\circ} \mathrm{I}$ - Janeiro a Junho de 2013

A atualidade é uma das essências dos relatos e está registrado no parágrafo XXIV. Peucer assegura que a origem e divulgação dos periódicos deram-se por conta da ânsia de satisfação da curiosidade humana, acompanhada de outras características (PEUCER, 2004, p. 26). Ao fim da tese, Peucer levanta, no parágrafo XXVIII, o critério da proximidade, como fator de satisfação de leitura (2004, p. 28).

No último parágrafo da tese, Peucer destaca os relatos periodísticos $(2004$, p. 28) e direciona a atenção aos variados gêneros dos periódicos da época, como os literários publicados na França, Inglaterra, Bélgica, Alemanha e Itália; os que prometem aos leitores coisas singulares com títulos curiosos, escritos na França e Holanda; os de eventos cívicos editados na capital holandesa e as publicações locais que se ocupam de diversos gêneros.

\section{Características (conceituais e históricas) jornalísticas, conforme Otto Groth}

As referências da obra de Otto Groth foram retiradas da apresentação do trabalho do alemão feitas por Angel Faus Belau (1966) para o espanhol. Faus Belau lembra que seu trabalho se constitui como um resumo da ciência jornalística de Otto Groth, indicando que "muchas de las modernas teorías sobre Periodismo e Información que hoy circulan, tienen su base en la obra del Dr. Groth, aún cuando los creadores de las mismas no le mencionem muchas veces en sus bibliografias" (1966, p. 16).

Tal referência implica que existem no Jornalismo características conceituais e estruturais básicas que definem o campo $^{2}$ e que já eram praticadas, em momentos históricos distantes da humanidade, sem que tivessem sido sistematizadas. Como visto, Peucer, há pouco mais de 300 anos, aglutinava em sua tese os usos informativos e 'periodísticos' que se estruturavam como fazeres que hoje se pode chamar de jornalísticos.

\footnotetext{
${ }^{2}$ Ao se referir a campo, não se discute, aqui, o conceito de Pierre Bourdieu. Usa-se o termo como um sinônimo de espaço ou setor específico ao Jornalismo.
} 
Estudos em Jornalismo e Mídia - Vol. $10 \mathrm{~N}^{\circ} \mathrm{I}$ - Janeiro a Junho de 2013

Groth também se preocupou em sistematizar as principais características que definem o Jornalismo, pois pretendia que a "Ciencia Periodística" alcançasse reconhecimento como ciência cultural independente (FAUS BELAU, 1966, p. 16). Groth enumera como a primeira característica do objeto de estudo da "Ciencia Periodística" a periodicidade. Groth a avalia como a mais notável característica dos jornais e revistas, diferenciando-os de outras publicações, como volantes ou panfletos.

Na definição de Groth, a periodicidade é "UN CONCEPTO DEL TIEMPO DE LA FORMA DEL PERIODIK”, onde o objeto volta-se a um ponto fixo de repetição, que é o homem. Seu conceito de periodicidade não considera necessária a igualdade da aparição, pois tal conota um sentido de regularidade. Tal sujeição à aparição fixa diminui, para Groth, a capacidade do jornal de seguir o ritmo acelerado da vida. "El periódico debe adaptarse a esta corriente de la vida, y esa libertad en sí, le da una apariencia de vida humana. La Periodicidad es, pues, RITMO DE VIDA" (FAUS BELAU, 1966, p. 48). A concepção de Groth de periodicidade é, contudo, diferente da de Dovifat, que a vê como repetição insistente, e à de Fattorello, que a define como uma técnica de repetição e capacitação do receptor.

O alemão pontua que a periodicidade está determinada pelas finalidades, necessidades e costumes humanos, e que essa medida varia de acordo com as condições sociais e culturais. Ela depende do progresso, dos transportes e serviço das notícias.

$\mathrm{Na}$ visão grothiana, a preeminência da periodicidade reside no fato de que, sem ela, a atualidade e universalidade do jornal seriam impossíveis. Além dessas duas características, o cumprimento da difusão depende da periodicidade, para penetrar num público amplo, fato que notícias publicadas esparsamente não conseguiriam atingir. Para o alemão, sem periodicidade, não existe ideia de jornal (FAUS BELAU, 1966, p. $50)$.

Depois da periodicidade, Groth pergunta-se sobre o que é oferecido diária e ininterruptamente. O questionamento diz respeito ao conteúdo dos jornais e revistas. Groth entende que as notícias tanto mais interessam quando se aproximam de cada qual e fazem com que esse(s) sinta(m)-se pertencente(s) a uma comunidade, visto que o 
Estudos em Jornalismo e Mídia - Vol. $10 \mathrm{~N}^{\circ} \mathrm{I}$ - Janeiro a Junho de 2013

homem transita por inúmeros grupos concomitantemente (sociedade geral, família, denominação religiosa, empresa). Para o alemão, cada esfera está carregada de atributos diferenciados e cada um observa os fatos sob pontos de vista distintos. É dever da Ciência Jornalística, nas palavras de Groth, encontrar-se com as perguntas que permeiam o "eu e o mundo", o "você e eu" e o "eu e a natureza". O teórico - num conceito original e fundamental para a investigação científico-jornalística - classifica essas relações de "Mundo Presente" (FAUS BELAU, 1966, p. 56). Groth destaca que é tarefa dos jornais transmitir conhecimento em relação a todas as questões acima, além de suprir a necessidade de aprendizado de toda a sociedade em todos os ramos da cultura e da vida dos indivíduos.

Faus Belau explica que a universalidade é 'onicompreensiva', o que significa que tudo o que existe e ocorre em qualquer lugar do mundo pode ser objeto (informativo) do jornal - por ser objeto dos mundos presentes dos indivíduos. O pensamento de Groth indica que o jornal compreende todas as facetas da sociedade, da natureza e da cultura, o que constitui a universalidade. Nesse sentido, a universalidade aborda somente o que diz respeito aos mundos presentes de seus leitores, e seus interesses. Por definição, ela é objetiva e subjetiva; sua estrutura é formada por relações objetivo-subjetivas. Esse arcabouço transfere significado ao homem. A composição da universalidade implica uma independência relativa das particularidades que se encontram no universo da matéria (FAUS BELAU, 1966, p. 57-58).

Por conta de seus elementos subjetivos e do trabalho de relatar o que é necessário sobre a realidade total objetiva para o presente de seus receptores, fica difícil demarcar limites à universalidade do jornal, que ora se observa claramente, ora de modo velado, em algumas vezes com mais força e em outras com menor expressão.

Groth distingue o atual, atualidade e novidade na terceira característica da "Ciencia Periodística". Para ele, atual tem duplo significado: pode ser o real, como também o presente. $\mathrm{O}$ atual como um problema novo, do dia. A atualidade representa os fatos atuais, presentes. Para Groth, o atual não é o mesmo que o novo. A atualidade se exprime numa relação fora do tempo e é um conceito de um objetivo. Significa o entrar 
Estudos em Jornalismo e Mídia - Vol. $10 \mathrm{~N}^{\circ} \mathrm{I}$ - Janeiro a Junho de 2013

de um ser/fato na presença e no agora. Em suma, o atual é o que tem uma relação para a presença. Já a novidade não se configura como um conceito de tempo. É uma relação mental entre o sujeito e o objeto até então desconhecido - pois a novidade é indicada no sujeito que não tinha ciência de algo até quando se inteirou dela. Groth expõe que, considerando o conceito de atualidade conforme seu conteúdo objetivo, similar ao de periodicidade, existe uma relação temporal de um ser ou de um acontecimento para uma parte do tempo objetivo.

A quarta característica da "Ciencia Periodística" de Groth, a difusão, é classificada como a segunda propriedade de forma da Ciência Jornalística, juntamente com a periodicidade, em contraste à universalidade e a atualidade, que para ele são características de conteúdo dos jornais. Por definição, a "Difusión está caracterizada potencial y objetivamente por la accesibilidad general de objeto. Indica la sinceridad, el ser abierto. [...] lo que es abierto para todo el mundo y que cualquiera puede tomar" (FAUS BELAU, 1966, p. 73). A difusão pressupõe acessibilidade irrestrita a todas as formas de comunicação efetuadas pelo jornal, de modo que ninguém seja excluído de receber o conteúdo. Tal significação objetiva da difusão se estende ao objeto da Ciência Jornalística, a imprensa periódica e, por conseguinte, à imprensa diária.

Groth considera que a difusão estende-se a todos os lugares: campo, cidade, países etc., e a todas as classes sociais. Porém, isso não significa que todos acessam o jornal. O número de leitores é determinado pelas circunstâncias geográficas, políticas, populacionais, sociais, econômicas, entre outras. Esses fatores, e os constrangimentos de cada esfera, delimitam, direta ou indiretamente, a intensidade da difusão.

\section{As epístolas bíblicas de Paulo: definição}

As cartas (epístolas) formam parte considerável do Novo Testamento da Bíblia, como destacam Miller e Huber (2006, p. 70), pois "se eliminássemos as cartas do Novo Testamento, perderíamos 21 dos 27 livros".

Dessas, 13 - e, para alguns (Hebreus) 14 -, quase a metade dos livros do Novo Testamento, são atribuídas a Paulo, apesar de a autenticidade autoral não ser garantida 
Estudos em Jornalismo e Mídia - Vol. $10 \mathrm{~N}^{\circ} \mathrm{I}$ - Janeiro a Junho de 2013

(MILLER; HUBER, 2006, p. 69). Os autores consideram as cartas de Paulo como os livros mais antigos do Novo Testamento - escritos, inclusive, antes mesmo de que as histórias de Jesus fossem sistematizadas pelos discípulos. Estudiosos, entre eles os supracitados, afirmam que 1 Tessalonicenses é a carta mais antiga de Paulo (p. 68).

Para a tradição, apresenta Barbaglio, 14 cartas compreendem a obra epistolar de Paulo: Romanos, 1 e 2 Coríntios, Gálatas, Efésios, Filipenses, Colossenses, 1 e 2 Tessalonicenses, 1 e 2 Timóteo, Tito, Filemon e Hebreus. Todavia, defende o autor, a pesquisa histórico-crítica dos últimos dois séculos tem verificado rigorosamente essa referência. Da investigação, algumas conclusões são universalmente reconhecidas, enquanto outras ainda são objeto de discussão. Nesse sentido, a epístola de Hebreus não pode ter sido escrita por Paulo; as cartas pastorais (1 e 2 Timóteo, Tito) são tardias, e atribuídas à escola dos discípulos do apóstolo. É muito discutida a autenticidade da carta aos Efésios. Críticos de renome, continua Barbaglio, questionam a autoria paulina das cartas aos Colossenses e a 2 Tessalonicenses; outros, porém, aceitam a última como do apóstolo. Assim, atribui-se a Paulo, consensualmente, sete cartas: Romanos, 1 e 2 Coríntios, Gálatas, Filipenses, 1 Tessalonicenses e Filemon (1989, p. 45).

O uso epistolar se configurava como uma estratégia de Paulo que, em vez de voltar correndo para uma igreja quando ocorria algum problema, escrevia cartas com as orientações necessárias aos seus correligionários (MILLER, HUBER, 2006, p. 68). Igualmente, na época de Paulo, filósofos, líderes religiosos e outros pensadores usavam cartas como uma ferramenta para espalhar os seus ensinos para uma ampla audiência. As cartas com esse propósitos ficaram conhecidas como epístolas, da palavra grega comum para "carta", explicam Miller e Huber (2006, p. 70).

O enviar cartas, prosseguem os autores, auxiliava no ministério do apóstolo. Por conta de suas constantes viagens, com o intuito de fundar igrejas ao longo do Império Romano, as epístolas o ajudavam a ministrar para mais de uma cidade ao mesmo tempo. Enquanto pregava em uma localidade, escrevia para líderes e colegas de congregações distantes, "geralmente com a intenção de que suas cartas fossem lidas em voz alta 
Estudos em Jornalismo e Mídia - Vol. $10 \mathrm{~N}^{\circ} \mathrm{I}$ - Janeiro a Junho de 2013

durante as cerimônias de adoração e [...] que circulassem em outras igrejas” (2006, p. $70)$.

Para a análise aplicada neste trabalho, assume-se e analisa-se apenas aquela que é considerada a autêntica obra do apóstolo, deixando de lado os outros escritos da tradição paulina. Outro recorte ainda é realizado e a carta a Filemon não compõe a análise, pois a pesquisa considera que tal seja uma epístola pastoral, que foge de um dos enquadramentos da pesquisa, o de difusão coletiva, uma das quatro características elementares do jornalismo defendidas por Otto Groth (apud FAUS BELAU, 1966). Assim, o objeto de pesquisa forma-se por seis cartas: Romanos, 1 e 2 Coríntios, Gálatas, Filipenses e 1 Tessalonicenses.

A composição epistolar paulina não se encerrou na redação das cartas, pois após a morte do apóstolo, as comunidades guardaram as cartas. Algumas se perderam, outras foram recolhidas, determinadas se fundiram e as pseudepígrafas, foram agregadas. Nasce daí o mito epistolar paulino, que rapidamente atingiu um grau de autoridade e passou a ser considerado Sagrada Escritura. "Com toda probabilidade, no final do século I, ou no início do II, na Grécia, na Itália, e na Ásia Menor possuía-se uma coleção com treze cartas: só a Carta aos Hebreus não estava incluída" (WICKENHAUSER, 1963, p. 34 apud BARBAGLIO, 1989, p. 46). O texto grego das cartas chegou até hoje pelos numerosos manuscritos antigos. Para Barbaglio (1989, p. 46), o papiro 46 - do ano 200, aproximadamente; os códigos Sinaíticos e Vaticano, do século IV; Alexandrino, do século V; de Efrém e Claromontano, século VI.

\section{Algumas marcas jornalísticas nas cartas bíblicas de São Paulo}

O resultado da análise das características (teórico-prática) do Jornalismo encontrada nas cartas bíblicas do apóstolo Paulo se divide em duas partes: a primeira trata da relação com os conceitos de Peucer; após, as ligações dos versos com noções conceituais da obra de Otto Groth. O quadro abaixo indica a panorama geral das porções dos escritos paulinos (versos bíblicos extraídos das cartas bíblicas) que se 
Estudos em Jornalismo e Mídia - Vol. $10 \mathrm{~N}^{\circ} \mathrm{I}$ - Janeiro a Junho de 2013

aproximam das principais características conceituas e históricas do Jornalismo na perspectiva de Tobias Peucer (2004).

\begin{tabular}{|c|c|c|c|c|c|c|}
\hline $\begin{array}{c}\text { Características } \\
\text { do Jornalismo, } \\
\text { segundo Peucer/ } \\
\text { Epístolas de São } \\
\text { Paulo }\end{array}$ & $\mathbf{R m}$ & $1 \mathrm{Co}$ & $2 \mathrm{Co}$ & Gl & $\mathbf{F p}$ & 1Ts \\
\hline $\begin{array}{c}\text { Factualidade } \\
\text { (Parágrafo III) }\end{array}$ & $2: 24$ & $\begin{array}{c}1: 11 ; \\
3: 1-6 ; \\
5: 1 ; \\
11: 18-21 ; \\
15: 3-8 ; 15: 29\end{array}$ & $\begin{array}{c}1: 8-11 ; \\
2: 12-13 \\
7: 5-16 \\
8: 1-6 \\
8: 16-17 \\
9: 1-5 \\
11: 23-33 \\
12: 7-8\end{array}$ & $\begin{array}{c}1: 6-7 \\
1: 13-24 \\
2: 1-14 \\
3: 13-20\end{array}$ & $\begin{array}{l}1: 12-17 \\
4: 15-18\end{array}$ & $\begin{array}{c}1: 6-9 \\
2: 1-2 \\
2: 9 \\
2: 13-16 \\
3: 1-6\end{array}$ \\
\hline $\begin{array}{c}\text { Testemunho } \\
\text { ocular/ } \\
\text { Autopsia } \\
\text { (Parágrafo X) }\end{array}$ & $\begin{array}{c}1: 8 \\
15: 18 \\
15: 26 \\
16: 19 \\
\end{array}$ & $15: 3-8$. & $\begin{array}{c}8: 1-6 \\
11: 23-33 \\
12: 7-8\end{array}$ & $\begin{array}{l}1: 6-7 \\
2: 1-14\end{array}$ & $4: 15-18$ & $\begin{array}{c}1: 6-9 \\
2: 13-16\end{array}$ \\
\hline $\begin{array}{c}\text { Interesse } \\
\text { público } \\
\text { (Parágrafo XI) }\end{array}$ & $15: 14-15$ & $\begin{array}{c}2: 9 \\
5: 1 ; \\
15: 51-52\end{array}$ & $\begin{array}{c}2: 1-4 \\
7: 2-16 \\
8: 16-17 \\
9: 1-5\end{array}$ & $3: 17-20$ & $\begin{array}{l}2: 19-30 \\
4: 15-18\end{array}$ & $\begin{array}{c}1: 6-9 \\
4: 14-17\end{array}$ \\
\hline $\begin{array}{c}\text { Acontecimentos } \\
\text { insólitos/ } \\
\text { Notoriedade } \\
\text { (Parágrafo XV) } \\
\end{array}$ & $\begin{array}{l}4: 19-20 \\
5: 7-8\end{array}$ & $\begin{array}{c}1: 23 \\
15: 4 \\
15: 29 \\
15: 51-52 \\
\end{array}$ & & & & $4: 14-17$ \\
\hline $\begin{array}{c}\text { Linguagem } \\
\text { acessível } \\
\text { (Parágrafo XXII) }\end{array}$ & & $\begin{array}{c}1: 17 \\
2: 1,4 \\
4: 20\end{array}$ & & & & \\
\hline $\begin{array}{c}\text { Atualidade } \\
\text { (Parágrafo } \\
\text { XXIV) }\end{array}$ & $\begin{array}{c}2: 24 \\
3: 21-26 \\
7: 7 \\
15: 14-15\end{array}$ & $\begin{array}{c}1: 11 ; \\
3: 1-6 ; \\
11: 18-21 \\
15: 3-8 \\
15: 29\end{array}$ & $\begin{array}{l}8: 1-6 \\
9: 1-5\end{array}$ & $\begin{array}{c}1: 6-7 \\
2: 1-14 \\
3: 13-20\end{array}$ & $\begin{array}{l}1: 12-17 \\
4: 15-18\end{array}$ & $\begin{array}{c}1: 6-9 \\
2: 1-2 \\
2: 13-16 \\
3: 1-6\end{array}$ \\
\hline $\begin{array}{l}\text { Proximidade } \\
\text { (Parágrafo } \\
\text { XXVIII) }\end{array}$ & $\begin{array}{c}3: 22 \\
15: 14-15\end{array}$ & $\begin{array}{c}3: 1-6 ; \\
5: 1 ; \\
11: 18-21 \\
15: 6-8 \\
15: 29\end{array}$ & $\begin{array}{c}1: 14-16 \\
2: 1-4 \\
7: 2-16 \\
8: 16-17 \\
9: 1-5 \\
10: 10-11 \\
\end{array}$ & $1: 6-7$. & $\begin{array}{l}1: 12-17 \\
2: 19-30 \\
4: 15-18\end{array}$ & $\begin{array}{c}2: 9 \\
2: 13-16 \\
3: 1-6 \\
4: 14-17\end{array}$ \\
\hline $\begin{array}{c}\text { Jornalismo } \\
\text { segmentado } \\
\text { (Parágrafo XIX) }\end{array}$ & $\begin{array}{c}\text { Plano da } \\
\text { salvação; } \\
\text { Exortações } \\
\text { acerca dos } \\
\text { deveres } \\
\text { cristãos. }\end{array}$ & $\begin{array}{l}\text { Purificação da } \\
\text { igreja de } \\
\text { falsos } \\
\text { conceitos. }\end{array}$ & $\begin{array}{c}\text { Defesa do } \\
\text { apostolado de } \\
\text { Paulo. }\end{array}$ & $\begin{array}{l}\text { Justificação } \\
\text { pela fé; } \\
\text { Advertências } \\
\text { contra a } \\
\text { reversão ao } \\
\text { judaísmo; } \\
\text { Vindicação do } \\
\text { apostolado de } \\
\text { Paulo. }\end{array}$ & Jesus Cristo. & $\begin{array}{c}\text { Conselhos e } \\
\text { exortações } \\
\text { para os } \\
\text { dilemas da } \\
\text { igreja local. }\end{array}$ \\
\hline
\end{tabular}

QUADRO 1 - Relação características do Jornalismo (PEUCER) e versículos das epístolas paulinas Fonte: Os autores 
Estudos em Jornalismo e Mídia - Vol. $10 \mathrm{~N}^{\circ} \mathrm{I}$ - Janeiro a Junho de 2013

$\mathrm{Na}$ (extensa) obra de Otto Groth, encontram-se as características que definem o Jornalismo. O teórico propõe a "Ciencia Periodística" como ciência cultural independente, com objeto de estudo próprio: jornais, revistas e as 'folhas' na sua integralidade, em detrimento de um mero estudo de conteúdo (FAUS BELAU, 1966, p. 25). Os versos (notícias) que ocorrem nas características do Jornalismo, segundo Otto Groth, em sua maioria - excetuando apenas três da epístola aos Romanos -, situam-se também em pelo menos uma categorização de Peucer. O quadro abaixo sistematiza os versos das cartas bíblicas paulinas que dialogam com as características conceituas do Jornalismo, conforme Groth (FAUS BELAU, 1966).

\begin{tabular}{|c|c|c|c|c|c|c|}
\hline $\begin{array}{l}\text { Características do } \\
\text { Jornalismo, cf. } \\
\text { Groth/Epístolas } \\
\text { de São Paulo }\end{array}$ & $\mathbf{R m}$ & $1 \mathrm{Co}$ & $2 \mathrm{Co}$ & Gl & Fp & 1Ts \\
\hline Universalidade & $\begin{array}{c}1: 16 \\
2: 24 \\
3: 21-26 \\
8: 3 \\
15: 8-9\end{array}$ & $\begin{array}{c}1: 11 ; \\
3: 1-6 ; \\
5: 1 ; \\
11: 18-21 \\
15: 3-8 \\
15: 29\end{array}$ & $\begin{array}{c}1: 8-11 \\
2: 12-13 \\
7: 5-16 \\
8: 1-6 \\
8: 16-17 \\
9: 1-5 \\
11: 23-33 \\
12: 7-8\end{array}$ & $\begin{array}{c}1: 6-7 \\
1: 13-24 ; \\
2: 1-14 ; \\
3: 13-20\end{array}$ & $\begin{array}{l}\text { 1:12-17; } \\
2: 19-30 \\
4: 15-18\end{array}$ & $\begin{array}{c}1: 6-9 \\
2: 1-2 \\
2: 9 \\
2: 13-16 ; \\
3: 1-6 \\
4: 14-17\end{array}$ \\
\hline Atualidade & $\begin{array}{c}2: 24 \\
3: 21-26 \\
7: 7 \\
15: 14-15\end{array}$ & $\begin{array}{c}1: 11 \\
11: 18-21 \\
15: 3-8 \\
15: 29\end{array}$ & $\begin{array}{l}8: 1-6 \\
9: 1-5\end{array}$ & $\begin{array}{c}1: 6-7 \\
2: 1-14 \\
3: 13-20\end{array}$ & $\begin{array}{l}1: 12-17 \\
4: 15-18\end{array}$ & $\begin{array}{c}1: 6-9 \\
2: 1-2 \\
2: 13-16 \\
3: 1-6\end{array}$ \\
\hline
\end{tabular}

QUADRO 2 - Relação características do Jornalismo (GROTH) e versículos das epístolas paulinas Fonte: Os autores

Dos 29 parágrafos que compõem a tese de Peucer, destacam-se, aqui, oito que podem ser relacionados com versículos das epístolas paulinas. Ao todo, o estudo indica 46 conjuntos de versículos nas seis epístolas paulinas que podem ser relacionadas com as noções peucerianas de Jornalismo. As características jornalísticas, conforme Peucer, que foram encontradas nas cartas de Paulo pelo estudo, são factualidade (parágrafo III), testemunho ocular/autopsia (parágrafo $\mathrm{X}$ ), interesse público (parágrafo XI), acontecimentos insólitos/notoriedade (parágrafo XV), linguagem acessível (parágrafo XXII), atualidade (parágrafo XXIV), proximidade (parágrafo XXVIII) e jornalismo segmentado (parágrafo XIX). 
Estudos em Jornalismo e Mídia - Vol. $10 \mathrm{~N}^{\circ} \mathrm{I}$ - Janeiro a Junho de 2013

Por sua vez, as categorias jornalísticas conceituadas por Otto Groth e encontradas nas cartas de Paulo são periodicidade, universalidade, atualidade e difusão. A pesquisa localizou 34 conjuntos de versículos nas seis epístolas paulinas que dialogam com as noções grothianas de Jornalismo.

Vale situar que as cartas também apresentam várias características literárias, teológicas (e jornalísticas) ao mesmo tempo. Paulo não tinha a intenção de escrever apenas um relato informativo, mas também transmitir orientações morais-filosófico-teológicas, repreender, saudar seus correligionários, entre outras ações efetuadas pelo discurso. E, essas possibilidades misturam-se ao longo das epístolas.

\section{Considerações finais}

Ao escrever cartas, o objetivo de Paulo era primeiro o de instruir, doutrinar, conservar, e até criticar e conflitar com os interlocutores. Não obstante, Paulo, como escritor autorizado, transmitia todo tipo de informações referente à surgente religião cristã. Tais relatos contêm notícias dos fatos testemunhados por ele, de interesse comum, singulares, atuais, próximos, descritos numa linguagem acessível, voltado para diferentes demandas, para se remeter à classificação de Peucer. Também, conforme os padrões de Groth, eram divulgados periodicamente, mediante as possibilidades, carregados de universalidade, atualidade, com difusão aberta.

Além das notícias do cotidiano, as cartas paulinas tratavam da 'boa notícia', o evangelho - etimologicamente, a palavra 'evangelho' vem do grego evangélion e quer dizer 'boa notícia', 'boa nova'; o sacrifício de Jesus Cristo pela raça humana. E, pois, se não vista como um suporte jornalístico, as cartas, no mínimo, podem ser consideradas como uma forma embrionária de jornalismo. Lógico que Paulo não tinha a intenção de exercer uma função jornalística, como a concebemos na contemporaneidade, porém, sua atuação nos faz pensar as cartas, ao menos, como formas protojornalísticas. 
Estudos em Jornalismo e Mídia - Vol. $10 \mathrm{~N}^{\circ} \mathrm{I}$ - Janeiro a Junho de 2013

Por fim, pode-se pensar que as epístolas paulinas podem se reunir ao grupo dos fenômenos pré-jornalísticos do mundo antigo, com base nos exemplos de Jorge Pedro Sousa (2008). E a proposta das considerações e informações contidas no presente texto se constitui em um desafio/esforço de suscitar reflexões no campo para que outros estudos sobre os livros bíblicos, e uma possível relação com o Jornalismo, sejam realizados.

\section{Referências bibliográficas}

BARBAGLIO, Giuseppe. As cartas de Paulo, I. Tradução de José Maria de Almeida. São Paulo: Loyola, 1989. (Coleção bíblica Loyola, v. 4).

BELTRÃO, Luiz. Iniciação à filosofia do jornalismo. 2. ed. São Paulo: Edusp; Com-Arte, 1992.

Jornalismo opinativo. Porto Alegre: Sulina, 1980.

BÍBLIA Sagrada. Nova Versão Internacional. São Paulo: Vida, 2000.

BRUCE, F. F. Paulo: o apóstolo da graça, sua vida, cartas e teologia. Tradução de Hans Udo Fuchs. São Paulo: Shedd Publicações, 2003.

CHAPARRO, Manuel Carlos da Conceição. Carta. In: MARQUES DE MELO, José (Org.). Gêneros jornalísticos na Folha de S. Paulo. São Paulo: FTD, 1992, p. 63-74.

FAUS BELAU, Angel. La ciencia periodística de Otto Groth. Pamplona: Instituto de Periodismo de la Universidad de Navarra, 1966.

LEMOS, Alcides. Cartas de leitores. Cartas (ainda) fechadas. In: NEOTTI, Clarêncio, (Coord.). Comunicação e consciência crítica. São Paulo, Loyola, 1979, p. 191-213.

MARQUES DE MELO, José. Jornalismo opinativo: gêneros opinativos no jornalismo brasileiro. 3. ed. rev. e ampl. Campos do Jordão: Mantiqueira, 2003.

MILLER, Stephen M.; HUBER, Robert V. A bíblia e sua história. Barueri: Sociedade Bíblica do Brasil, 2006.

PEUCER, Tobias. Os relatos jornalísticos. Tradução de Paulo da Rocha Dias. Estudos em Jornalismo e Mídia, Florianópolis, v. 1, n. 2, p. 13-29, jul./dez. 2004 . Disponível em:

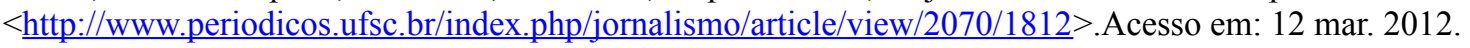

PIZARROSO QUINTERO, Alejandro (Coord.). História da imprensa. Lisboa: Planeta Editora, 1996

PORTER, J. R. A Bíblia - guia ilustrado das escrituras sagradas: história, literatura e religião. Tradução de Eliana Vieira Rocha e Maria da Anunciação Rodrigues. São Paulo: Publifolha, 2009. (Coleção referência).

RIZZINI, Carlos. O jornalismo antes da tipografia. São Paulo: Nacional, 1977.

SCHENEIDER, Ingrid Sculze. A imprensa na Alemanha. In: PIZARROSO QUINTERO, Alejandro (Coord.). História da imprensa. Lisboa: Planeta Editora, 1996. p. 107-152. 
Estudos em Jornalismo e Mídia - Vol. $10 \mathrm{~N}^{\circ} \mathrm{I}$ - Janeiro a Junho de 2013

SOUSA, Jorge Pedro (2008). Uma história breve do jornalismo no Ocidente. Disponível em: $<$ http://www.bocc.ubi.pt/pag/sousa-jorge-pedro-uma-historia-breve-do-jornalismo-no-ocidente.pdf $>$. Acesso em: 11 jun. 2012.

SOUSA, Jorge Pedro. Tobias Peucer: progenitor da Teoria do Jornalismo. Estudos em Jornalismo e Mídia, Florianópolis, v. 1, n. 2, p. 31-46, jul./dez. 2004. Disponível em: $<$ http://www.periodicos.ufsc.br/index.php/jornalismo/article/view/2071/1813 > . Acesso em: 12 abr. 2012.

TAMBOSI, Orlando. Tobias Peucer e as origens do jornalismo. Estudos em Jornalismo e Mídia, Florianópolis, v. 1 , n. 2 , p. 49-59, jul./dez. 2004. Disponível em: <http://www.periodicos.ufsc.br/index.php/jornalismo/article/view/2072/1814>. Acesso em: 12 abr. 2012.

Este artigo e todo o conteúdo da Estudos em Jornalismo e Mídia estão disponíveis em http://www.periodicos.ufsc.br/index.php/jornalismo/index 